\title{
Research on Low Voltage Ride through of the Grid-Connected PV System
}

\author{
Kaiting LI ${ }^{\mathrm{a}}$, Junjie QIAN,Huaren WU,Tianran LI,Jianfei YANG \\ School of Electrical and Automation Engineering, Nanjing Normal University, 210042 Nanjing, China \\ a18120178689@163.com
}

\begin{abstract}
Keywords: PV power system, Maximum Power Point Tracking (MPPT), Low Voltage Ride Through(LVRT),DC voltage control,duty cycle.
\end{abstract}

Abstract. With the increasing capacity of PV systems in the grid, the grid-connected PV systems will have negative impacts on the grid in the case of a disturbance or a fault. In this study, a strategy of 'DC voltage control' is adopted. During the period of low voltage ride through (LVRT), the duty cycle of the boost circuit is adjusted to reduce the output power of the PV battery so that the DC side voltage will be limited. Also reactive power is provided according to the depth of grid voltage sags to support voltage recovery of the grid. Consequently LVRT is realized successfully. Finally, the control strategy is verified in MATLAB/SIMULINK.

\section{Introduction}

The public know the disadvantages of fossil fuel,which have driven climate changes and go exhausted, so photovoltaic(PV) generation systems have been broadly applied [1]-[4]. In the rapid development of the PV systems, the impacts of them on the grid are becoming increasingly apparent. With the increasing capacity of PV systems, they bring serious challenges to the stable operation of the grid especially under the fault conditions because of the characteristics of random and intermittent. Consequently Low Voltage Ride Through (LVRT) has been proposed and applied widely.The introduction of LVRT brings benefits to the grid while it also increases the design difficulty of PV inverters. When the grid has faults or the voltage drops, there may be a series of problems such as overvoltage, overcurrent and the surge of the imbalance of the two sides[5]-[8].

In order to solve the imbalance of energy during the period of LVRT, this paper adopts a strategy of 'DC voltage control (DCVC)' to regulate the duty cycle of the boost circuit. During the period of LVRT, the MPPT is stopped and the strategy of DCVC is used. The ouput power of the PV battery will be reduced so that the DC side voltage will not be too high. Also reactive power is provided to the grid to support voltage recovery. Consequently LVRT is realized successfully. Finally, the control strategy is verified by building model in MATLAB/SIMULINK.

\section{LVRT Control}

Usually PV grid-connected power generation systems can be divided into three types: single-level, bipolar and multi-level. This paper studies the bipolar grid-connected PV system. Fig.1 shows the direct power control diagram of the PV grid-connected system. The first level in Fig. 1 is the control of the DC-DC boost circuit . It mainly realizes the control of MPPT. PV cells have different Maximum Power Points(MPP) under different conditions, so the boost circuit is used to change the duty cycle to adjust the operating voltage. The MPP of the PV cells is tracked using the 'Perturb \& Observe' technique, which is widely studied and adopted at present[12].The second level is the control of the DC-AC converter .VSC inverter is used and the AC voltage is obtained based on direct power control.

The voltage equation of the output voltage of the grid-connected inverter is derived by Kirchhoff Law from Fig. 1:

$$
U_{i a b c}-E_{a b c}=R_{3} I_{a b c}+L_{3} \frac{d I_{a b c}}{d t}
$$




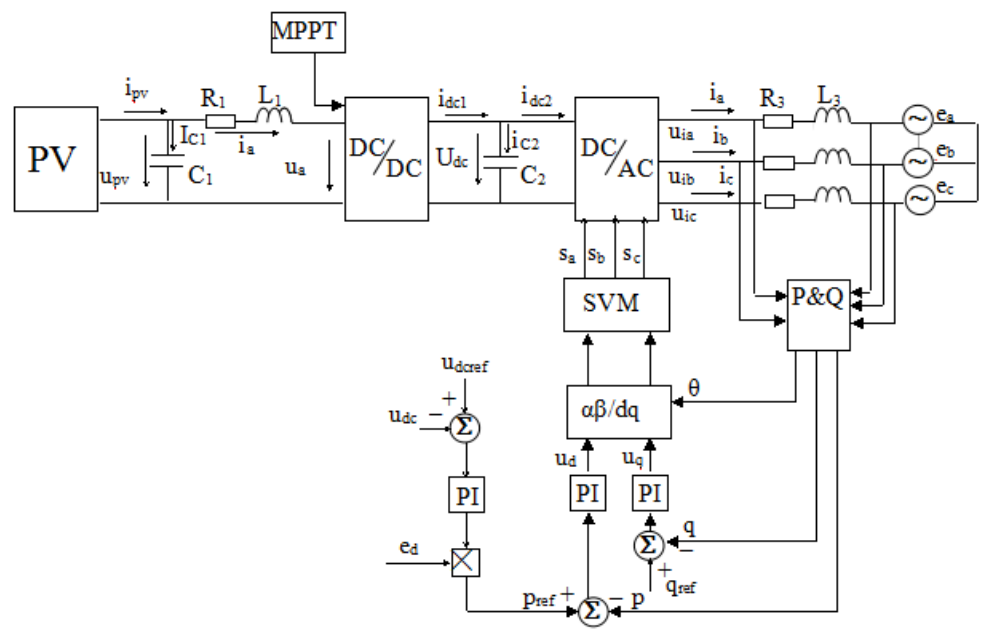

Fig. 1. Direct power control diagram of the PV grid-connected system Using Park transformation on it can get the following equation in (2):

$$
U_{i d q 0}-E_{d q 0}=R_{3} I_{d q 0}+L_{3} \frac{d I_{d q 0}}{d t}+L_{3}\left[\begin{array}{c}
-\omega I_{q} \\
\omega I_{d} \\
0
\end{array}\right]
$$

Thus the direct power control equation in (3) can be obtained:

$$
\left\{\begin{array}{l}
p_{r e f}=e_{d}\left(K_{P}+\frac{K_{I}}{s}\right)\left(u_{d c r e f}-u_{d c}\right) \\
u_{d}=\left(K_{P d}+\frac{K_{I d}}{S}\right)\left(p_{r e f}-p\right) \\
u_{q}=\left(K_{P q}+\frac{K_{I q}}{s}\right)\left(q_{r e f}-q\right)
\end{array}\right.
$$

Requirement for LRVT. LVRT means that the time when the grid voltage drops, the PV system can maintain to connect the grid.The PV generation system can even provide certain reactive power to support the grid recovery until the grid comes back to normal, so as to pass through this low voltage time. PV inverters are required to stay connected with the grid when the grid voltage sag is above curve 1 in Fig. 2 according to the SGCC's standard [10].

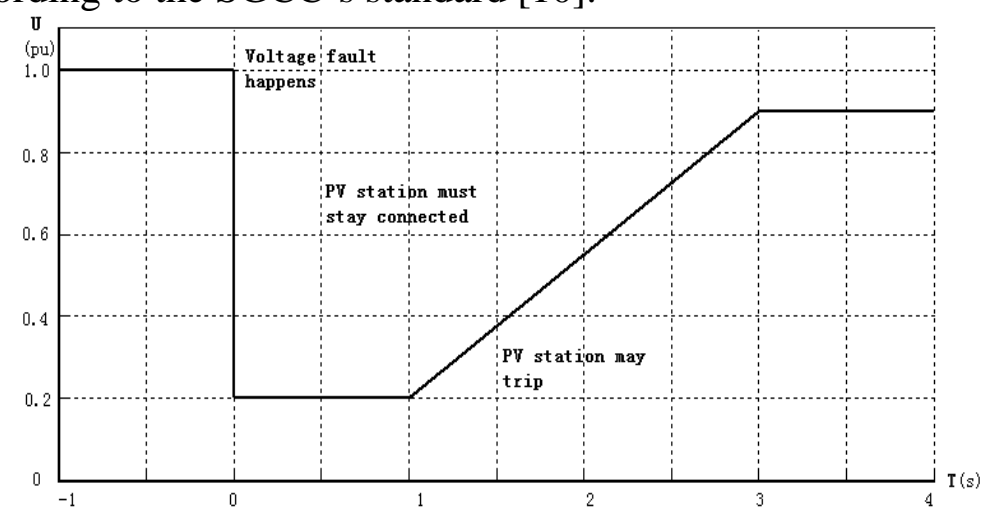

Fig.2. Typical low voltage ride through requirement of SGCC

Control strategy of LRVT. When the system is in normal operation, the output power of PV cells and the output power of the inverter can keep in balance. If the grid has a short circuit fault, the voltage of the grid will significantly reduce and the output power of the inverter will obviously reduce. If the output power of the PV battery is constant, the power imbalance will cause the voltage of the 
DC side to increase. A strategy of DCVC is adopted to regulate the duty cycle. The MPPT control strategy is used in normal operation. During the period of LVRT, the duty cycle of the boost circuit is adjusted by DCVC module. The output power of the PV battery will be reduced so that the DC side voltage will not be too high.DCVC is achieved by using PID control.Also reactive power is provided to the grid for supporting voltage recovery of the grid according to the depth of grid voltage sags. The

relationship of the dynamic reactive current Iq and the depth of grid voltage sags can be obtained in (4) [9].

$$
\left\{\begin{array}{l}
\frac{I_{q}}{I_{N}}=0, \frac{U}{U_{N}}>0.9 \\
\frac{I_{q}}{I_{N}}=-2 \frac{U}{U_{N}}+2,0.5<\frac{U}{U_{N}}<0.9 \\
\frac{I_{q}}{I_{N}}=1, \frac{U}{U_{N}} \leq 0.5
\end{array}\right.
$$

Both the active current and the reactive current should not exceed 1.1 times of the rated current, which can be described by the following inequality in (5):

$$
\sqrt{I_{d}^{2}+I_{q}^{2}} \leq 1.1 I_{N}
$$

The control strategy is shown in Fig.3.

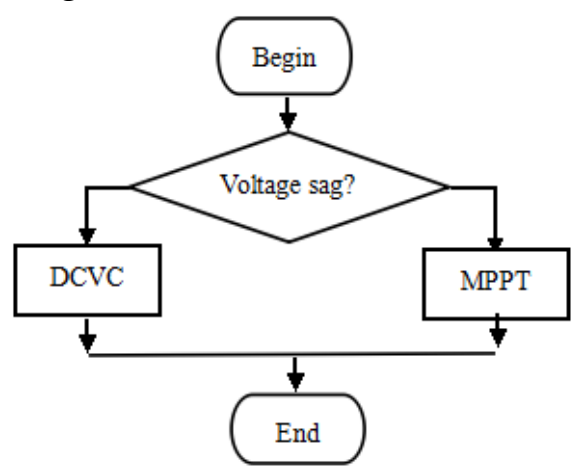

Fig. 3. Duty cycle control strategy

\section{Model Of Grid-Connected PV System}

Refer to the MATLAB example. A $100-\mathrm{kW}$ PV array is connected to a $25-\mathrm{KV}$ grid via a DC-DC boost converter and a three-phase three-level Voltage Source Converter (VSC). MPPT and LVRT are implemented in the boost converter .The model contains the following components: PV array, DC-DC boost converter, 3-level 3-phase VSC, three-phase coupling transformer and the utility grid. The 100-kW PV array consists of 66 strings of 5 series-connected 305.2-W modules connected in parallel $(100.7 \mathrm{~kW})$. The number of series-connected cells is 96 . Open-circuit voltage is $64.2 \mathrm{~V}$. Short-circuit current is 5.96A. At maximum power, the voltage is $54.7 \mathrm{~V}$, the current is $5.58 \mathrm{~A}$. The model shows in the Fig.4. Other model parameters can be found in [13]. 


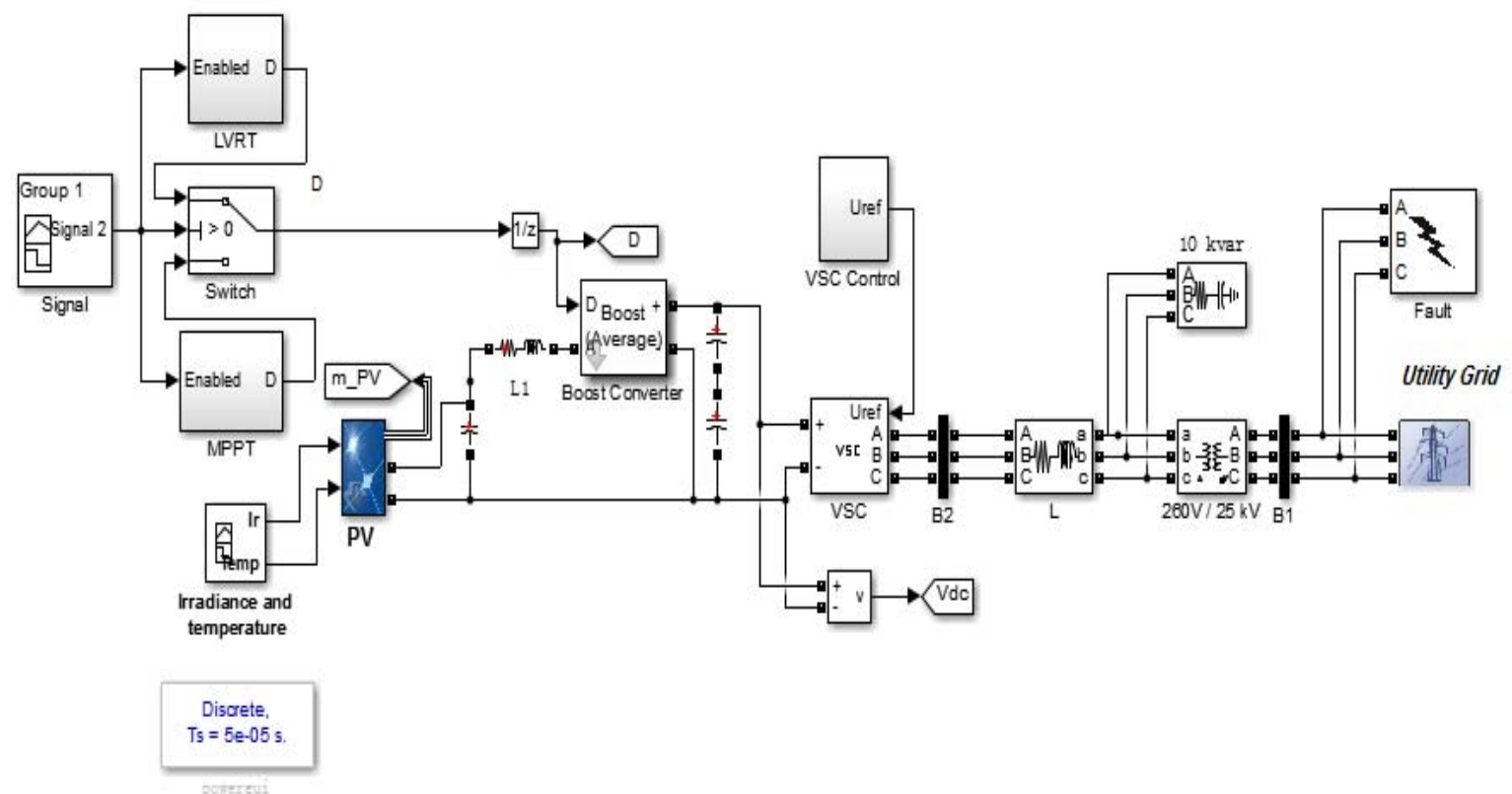

Fig. 4 Simulink model of grid-connected PV system

\section{Simulation Analysis}

LVRT simulation analysis.'without DCVC strategy' means that during the period of LVRT,only MPPT is used and DCVC is not used. Fig.5 (a) shows that the DC voltage exceeds about 70\% more than the normal operating voltage without DCVC. Fig.5 (b) shows that DC side voltage can be quickly adjusted to 500V and modulation ratio is well with DCVC. Fig.6 shows the active power and reactive power. Fig.6(a) shows that the active power and reactive power have a violent oscillation and the amplitude is so large that the inverter will be burned out without DCVC strategy. When the DCVC strategy is used, the reactive power is showed in Fig. 6(b). Three-phase voltage and current at $25 \mathrm{kV}$ bus are showed in Fig.7. The oscillation and amplitude of the current are reduced.
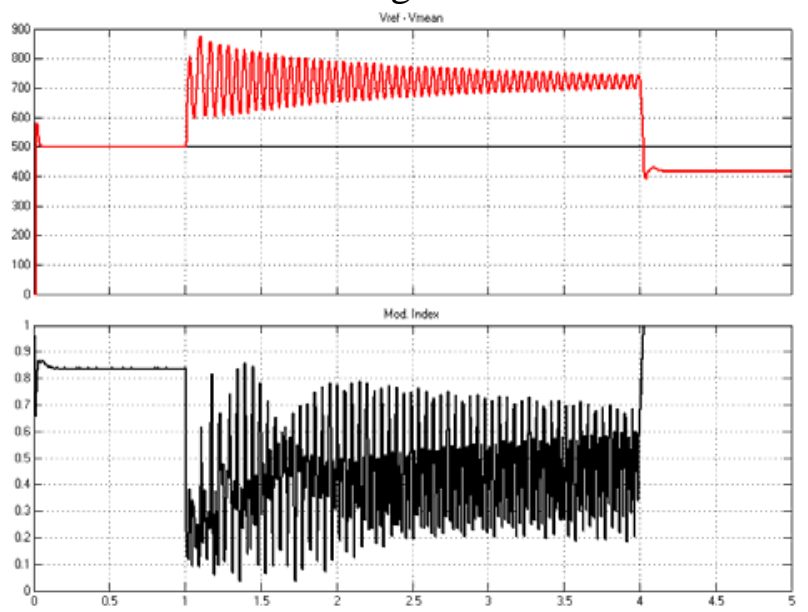

(a)Without DCVC strategy
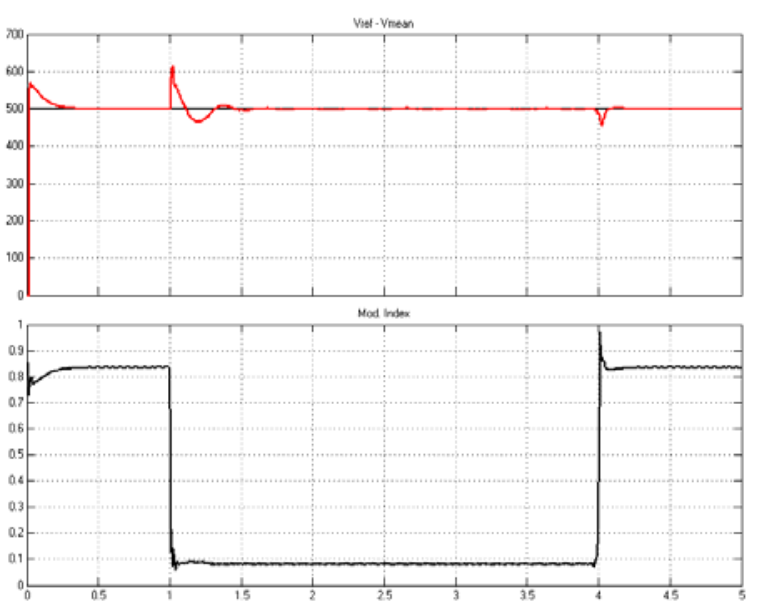

(b) Using DCVC Strategy

Fig.5 Waveforms of DC side voltage and modulation ratio 


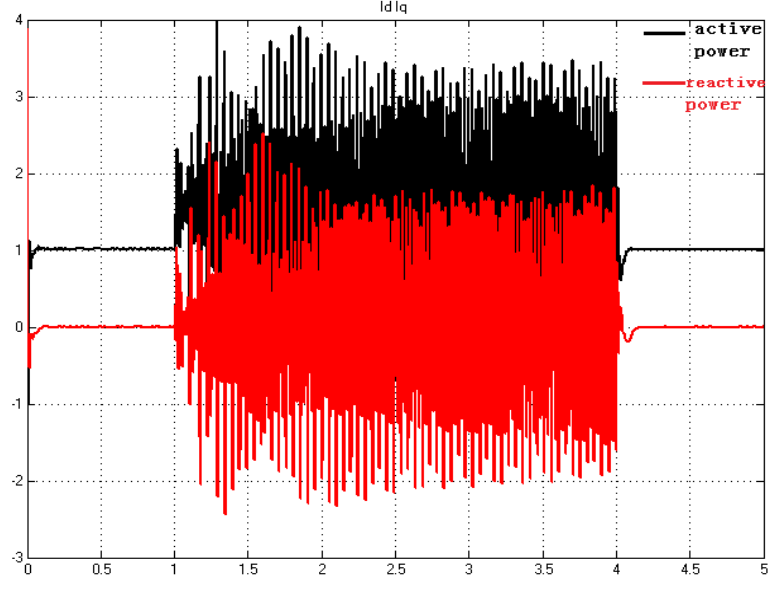

(a)Without DCVC strategy

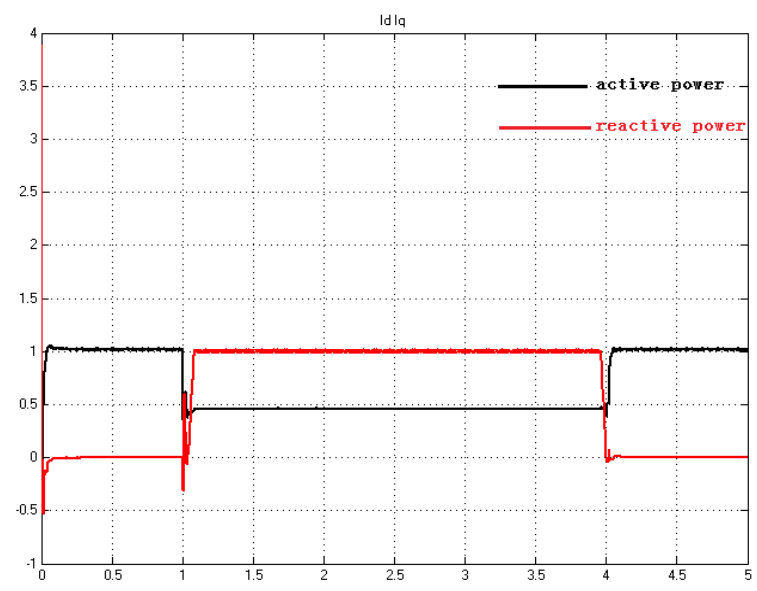

(b)Using DCVC strategy

Fig.6 Waveforms of active power and reactive power
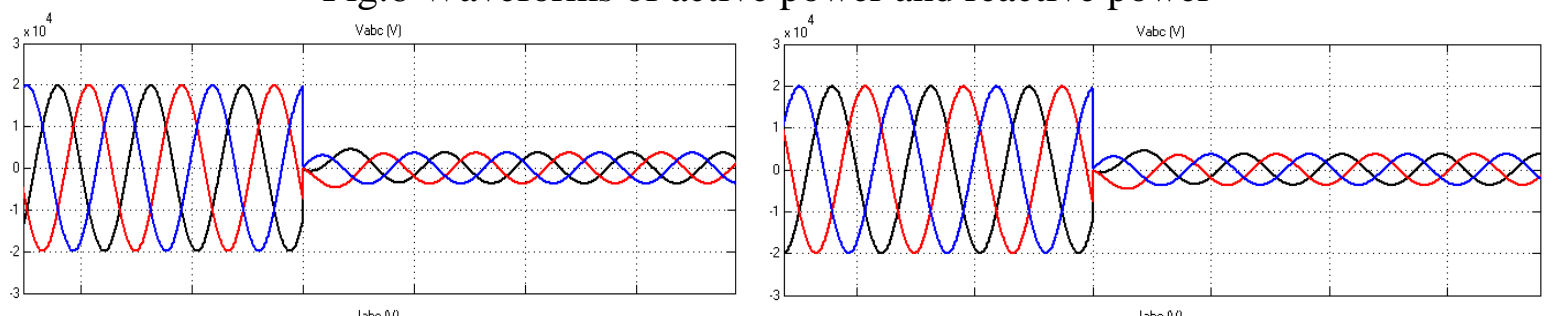

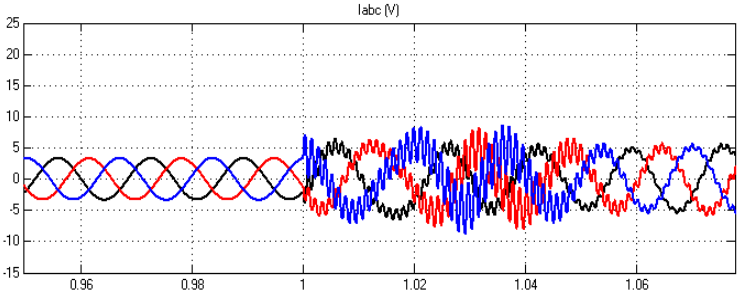

(a)Without DCVC strategy

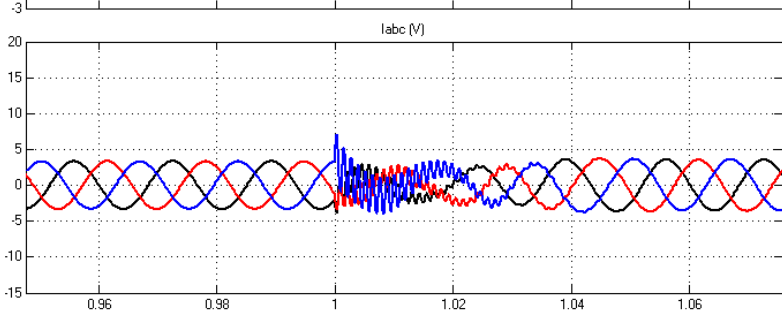

(b) Using DCVC strategy

Fig.7 Three-phase voltage and current at $25 \mathrm{kV}$ bus

\section{Conclusions}

In this paper, the mathematical model and working principle of grid-connected PV generation system are introduced, and the MPPT strategy of normal operation and the LVRT strategy are introduced.When the three-phase voltage of the grid drops,the DCVC is adopted to adjust the duty cycle to limit the rise of the DC side voltage.Also reactive power is provided to support voltage recovery according to the depth of grid voltage sags.The low voltage ride through succeeds.The results of the simulation show that the LVRT of the PV power system can be achieved by using the control strategy.The control strategy can be verified effective and makes the theoretical preparation for the large-scale PV power systems to connect the grid.

\section{Acknowledgements}

This work was financially supported by the National Natural Science Foundation of China (51177074,51407095) and Jiangsu province natural science foundation (BK20151548).

\section{References}

[1] S. Eftekharnejad, V. Vittal, G. T. Heydt, B. Keel, and J. Loehr, "Impact of increased penetration of photovoltaic generation on power systems, ”IEEE Trans. Power Syst., vol. 28, no. 2, pp. 893 - 901, May 2013. 
[2] Y. Chen, C. Chen and K. Chen, "Modeling and Controller Design of an Autonomous PV module for DMPPT PV Systems," IEEE Trans. Power Electronics,vol. 29, no. 9, pp. 4723-4732, Sept. 2014.

[3] Dave Turcotte and Farid Katiraei, “Fault Contribution of GridConnected Inverters," in Proc. 2009 IEEE Electrical Power Conference, pp. 1-5.

[4] B. Yang, W. Li, Y. Zhao, and X. He, "Design and analysis of a grid-connected photovoltaic power system,” IEEE Trans. Power Electron., vol. 25, no. 4, pp. 992-1000, Apr. 2010.

[5] Islam, G. M. S., et al. "Low voltage ride through capability enhancement of grid connected large scale photovoltaic system." IECON 2011 - 37th Annual Conference on IEEE Industrial Electronics SocietyIEEE, 2011:884 - 889.

[6] Zheng, Fei, J. Zhang, and M. Ding. "A novel voltage sag generator for low voltage ride-through testing of grid-connected PV system." Computer Science and Automation Engineering (CSAE), 2012 IEEE International Conference onIEEE, 2012:136-140.

[7] Varma, R. K., et al. "Novel control of a PV solar system as STATCOM (PV-STATCOM) for preventing instability of induction motor load." Canadian Conference on Electrical and Computer Engineering2012:1 - 5.

[8] Bao, Xianwen, et al. "Low voltage ride through control strategy for high-power grid-connected photovoltaic inverter." Applied Power Electronics Conference and Exposition (APEC), 2013 Twenty-Eighth Annual IEEEIEEE, 2013:97 - 100.

[9] Wu, Yong Sih, et al. "A current control strategy for three-phase PV power system with low-voltage ride-through." Advances in Power System Control, Operation and Management (APSCOM 2012), 9th IET International Conference onIET, 2012:1-6.

[10] GB/T 19964-2012 Technical regulations of the photovoltaic powerstation connected to the power system[S].Beijing: State Grid Corporation of China,2012

[11] Yang, Yongheng, et al. "Suggested grid code modifications to ensure wide-scale adoption of photovoltaic energy in distributed power generation systems." Industry Applications Society Annual Meeting, 2013 IEEEIEEE, 2013.

[12] M. S. E. Moursi, H. H. Zeineldin, J. L. Kirtley, Jr., and K. Alobeidli, “A dynamic master/slave reactive power-management scheme for smart grids with distributed generation,” IEEE Trans. Power Del., vol. 29,no. 3, pp. 1157 - 1167, Jun. 2014.

[13] The MathWorks, Inc. SimPowerSystem use’s guide. 2014. 